\title{
A NATUREZA JURÍDICA DA DECISÃO QUE JULGA PROCEDENTE A AÇÃO DE FALÊNCIA
}

\author{
Daniel Gomes de Oliveira Guerreiro', Celina Rizzo Takeyama² \\ ${ }^{1}$ Acadêmico do Curso de Direito, Centro Universitário de Maringá - UNICESUMAR. daniel_guerreiro88@hotmail.com \\ ${ }^{2}$ Mestre em Direito, professora do curso de Direito da Unipar-Paranavaí. celinarizzo@gmail.com
}

\begin{abstract}
RESUMO
A presente pesquisa tem como escopo solucionar um tema que possui opiniões conflitantes perante os doutrinadores do Direito Empresarial, qual seja, a natureza jurídica da decisão que julga a ação de falência.

Para chegar à tal finalidade, será analisada a finalidade da falência, bem como as linhas gerais do processo de falência. Ademais, será feito o estudo da decisão que julga procedente a ação de falência, encerrando a fase de conhecimento e dando início à fase concursal ou falimentar propriamente dita, a fim de verificar quais efeitos ela produz, nos termos do art. 99, da Lei n. 0 11.101/2005.
\end{abstract}

Além do acima alinhavado, serão apresentadas as divergências doutrinárias a respeito da natureza jurídica da decisão que julga procedente a ação de falência, demonstrando os argumentos que levam os juristas a defenderem a natureza constitutiva ou a declaratória, bem como destacando que referida discussão ainda é levada aos tribunais pátrios, como, por exemplo, ocorreu no Recurso Especial N. 1.660 .198 - SP (2016/0086883-0), de Relatoria da Ministra Nancy Andrighi.

Ainda, sob a égide do CPC/2015, serão estudados os conceitos de sentença e de decisão interlocutória, bem como a classificação das decisões judiciais quanto à natureza do provimento jurisdicional (declaratória, constitutiva e condenatória, por exemplo).

Por fim, a decisão supracitada será criticamente analisada, conforme à sua finalidade no processo de falência, de seus efeitos e da classificação das decisões judiciais quanto à natureza jurídica do provimento, bem como será realizada a análise a partir de quando a decisão deverá produzir seus efeitos.

PALAVRAS-CHAVE: processo, falimentar, pronunciamento, judicial.

\section{INTRODUÇÃO}

A falência é o processo judicial de execução concursal contra devedor empresário juridicamente insolvente, sendo este fundamento primordial para o ajuizamento de uma ação de falência, nos termos da lei que regula a recuperação judicial, a extrajudicial e a

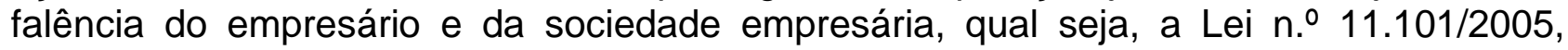
notadamente o artigo 94 do referido diploma legal. Nesta execução, há a reunião de todos os credores, ocorrendo a arrecadação de todos os bens do devedor, com a finalidade de tirar o devedor empresário do mercado e preservar a atividade.

A Lei de Recuperação Judicial e Falência foi promulgada em razão do fato de que os empresários e as sociedades empresárias geram empregos a diversos brasileiros, lucros ao Estado, bem como prestam serviços a um número incontável de pessoas. Assim, diante da função social da empresa, bem como do princípio da livre iniciativa, amparado pela Constituição Federal de 1988, é possibilitado que os empresários e as sociedades empresárias tenham um tratamento especial e diferenciado quando estão em situação de insolvência, diante de todos os efeitos nefastos que o processo de falência gera a toda sociedade.

Neste sentido, há de se mencionar que da sentença que decreta a falência, descrita no artigo 99 da LRF, é cabível a interposição do recurso de agravo de instrumento (art. 
1.015, do CPC/2015), diferentemente do que dispõe a legislação processual civil vigente, que promulga que, das sentenças, é cabível o recurso de apelação. A referida peculiaridade recursal nas ações de falência tem como objetivo evitar a protelação recursal, justificando assim a excepcionalidade que ocorre em decorrência da falência ter o rito disposto por uma lei especial, uma vez que o procedimento de interposição, processamento e julgamento, disposto no Código de Processo Civil de 2015, do agravo de instrumento, é, em tese, mais rápido do que o que envolve a apelação (MAMEDE, 2018).

No que tange à sentença que julga procedente a ação de falência, o mencionado pronunciamento judicial impõe efeitos ao empresário falido ou a sociedade empresária falida, bem como aos seus credores. Nesta senda, salienta-se que os efeitos estão dispostos nos artigos $81,102,103,115,77,116$ e, notadamente, no artigo 99, todos da Lei n.. 11.101/05.

Assim, a presente pesquisa tem como escopo solucionar a discussão doutrinária que há em relação a natureza jurídica da sentença que julga procedente a ação de falência.

Neste sentido, no que pertine à classificação trinária das naturezas jurídicas das decisões judiciais, "a sentença declaratória apenas "declara" a existência, a inexistência ou o modo de ser de uma situação jurídica. Já a sentença constitutiva pode criar, modificar ou extinguir uma situação jurídica (MARINONI, 2016)". E, por fim, destaca-se que a sentença condenatória é aquela caracterizada por aplicar a sanção, abrindo oportunidade para a execução.

Destarte, há autores, como Rubens Requião, que defendem que a natureza jurídica da decisão que julga procedente a ação de falência seria declaratória, mas há doutrinadores, como Waldo Fazzio Jr., que sustentam que a natureza jurídica da decisão que julga procedente a ação de falência é constitutiva. Ainda, há doutrinadores, como Gladston Mamede e José da Silva Pacheco que entendem que a natureza jurídica da sentença em debate não é constitutiva, tampouco somente declaratória.

Ademais, destaca-se que a divergência não está presente apenas na doutrina, uma vez que a discussão, muitas vezes, é levada aos tribunais superiores, como ocorreu no julgamento do Recurso Especial N. 1.660 .198 - SP (2016/0086883-0), em que a ilustre relatora, a Ministra Nancy Andrighi, baseou seu entendimento no sentido de que a natureza jurídica é declaratória, inovando quanto ao termo inicial dos efeitos gerados pela decisão.

Desta forma, verifica-se que é imperioso analisar criticamente, de acordo com a teoria geral do processo civil, os efeitos produzidos pela decisão jurídica que julga procedente a ação de falência, tendo em vista os efeitos que esta gera ao empresário ou a sociedade empresária insolvente, bem como aos seus credores, nos termos do artigo 99, da Lei $n$. . 11.101/2005, visto que uma decisão declaratória produz efeitos ex tunc e uma constitutiva produz efeitos ex nunc.

\section{JUSTIFICATIVA}

A presente pesquisa justifica-se à medida que não há um consenso jurídico em torno da natureza jurídica da decisão que julga a ação de falência, gerando grande insegurança jurídica a respeito de quando começam a ser produzidos seus efeitos.

A questão é tão séria que referida discussão ainda tem chegado aos tribunais superiores e sem perspectiva de que em breve haverá uma uniformização do entendimento e muito menos de que este seja coerente e juridicamente consistente.

Tanto é verdade que em recente decisão, a Ministra Nancy Andrighi apreciou a matéria em sede de julgamento de recurso especial, entendendo que a natureza era declaratória e como tal que produzia efeitos ex tunc. Porém inovou quanto ao entendimento relacionado ao momento em que referida decisão começa a produzir seus efeitos, ou seja, até quando deveria retroagir. 
Tudo isto torna-se grave à medida que se verifica que o art. 99, da Lei no $11.101 / 2005$ (LRF) prevê uma série de efeitos que são produzidos pela decisão que julga procedente a ação de falência, tais como a suspensão da fluência dos juros que recaem sobre as obrigações do falido e a suspensão do prazo prescricional das ações em face do falido, que, como é intuitivo, afetam diretamente todos os credores concursais envolvidos no processo.

Assim, tendo em vista que as decisões constitutivas produzem efeitos ex nunc e as declaratórias ex tunc, é imperioso determinar a natureza jurídica da decisão que julga a ação de falência, a fim de estabelecer o termo inicial dos inúmeros efeitos produzidos pela decisão regulada pelo art. 99, LRF. Ademais, ainda que se compreenda que ela produz efeitos ex tunc, é preciso definir com coerência jurídica até quando a decisão deve retroagir para fixar o termo inicial de seus efeitos, sem que tal importe em violação à teoria geral do processo.

Isto torna-se ainda mais grave, à medida que se tem consciência da crise econômica pela qual passa o país e do consequente número crescente de ações de falência, envolvendo diversos setores da sociedade (credores trabalhistas, fiscais, bancários, quirografários entre outros). Como consequência, fácil deduzir que sem estas definições realizadas de maneira coerente com o Ordenamento Jurídico pátrio, a insegurança jurídica permanecerá, afetando cada vez mais empresários em crise, seus inúmeros credores e o próprio Judiciário, com um número considerável de recursos para discutir referida matéria.

Assim, analisar criticamente - e sem violar a teoria geral do processo civil - qual é a natureza jurídica da decisão que julga procedente a falência, bem como o momento a partir do qual ela começa a produzir seus efeitos, torna-se imperativo.

\section{OBJETIVOS}

A pesquisa que ora se propõe tem por objetivo geral analisar qual a natureza jurídica da decisão que julga procedente a ação de falência, vale dizer, se declaratória ou constitutiva e, por consequência, analisar a partir de quando seus efeitos começam a ser produzidos.

Para tanto, tem-se como objetivos específicos:

Analisar a finalidade da falência, bem como as linhas gerais do processo de falência.

Estudar a decisão que julga procedente a ação de falência, encerrando a fase de conhecimento e dando início à fase concursal ou falimentar propriamente dita, a fim de verificar quais efeitos ela produz, nos termos do art. 99, da Lei no 11.101/ 2005.

Apresentar as divergências doutrinárias a respeito da natureza jurídica da decisão que julga procedente a ação de falência, demonstrando os argumentos que levam os juristas a defenderem a natureza constitutiva ou a meramente declaratória, bem como ressaltando que referida discussão ainda é levada aos tribunais pátrios, como ocorreu no Recurso Especial № 1.660.198 - SP (2016/0086883-0), de Relatoria da Ministra Nancy Andrighi.

Estudar o conceito de sentença e de decisão interlocutória no CPC/2015, bem como a classificação das decisões judiciais quanto à natureza do provimento jurisdicional (declaratória, constitutiva e condenatória).

Analisar criticamente a decisão que julga a ação de falência, à luz de sua finalidade no processo de falência, de seus efeitos e da classificação das decisões judiciais quanto à natureza jurídica do provimento, bem como analisar a partir de quando deverá a produzir seus efeitos.

\section{METODOLOGIA}


Utilizar-se-á o método bibliográfico, à medida que será analisada a doutrina empresarial a respeito da decisão que julga procedente a ação de falência e seus efeitos, bem como obras de Direito Processual Civil no que concerne à natureza jurídica das decisões e seus efeitos.

Da mesma forma, serão analisadas a legislação falimentar em vigor - com especial destaque para o art. 99, da Lei no 11.101/2005, que regula justamente a decisão que julga a ação de falência -, algumas decisões dos tribunais pátrios, especialmente o Recurso Especial № 1.660.198 - SP (2016/0086883-0), sob relatoria da Ministra Nancy Andrighi, a fim de possibilitar uma análise crítica mais consistente a respeito do tema ora proposto.

\section{DA FALÊNCIA}

Etimologicamente, a palavra "falência" tem sua origem no termo "fallere", do latim, que significa falsear ou enganar. Já a palavra "falência" pode ser definida como o ato ou efeito de falir, sendo este um verbo intransitivo. Logo, o adjetivo "falido" é empregado para caracterizar aquele que, sendo empresário ou sociedade empresária, não tem como pagar os seus credores.

Neste sentido, ressalta-se que é comum palavras como "insolvente", "falido" ou "quebrado" terem uma conotação negativa, degradante, diretamente ligadas com os adjetivos "caloteiro", "fraudador", "desonesto", e muitos outros.

Ademais, o fato de uma pessoa não conseguir pagar suas contas é, em diversos casos, motivo de vergonha para ela e isso advém de uma vasta herança histórica e cultural, como, por exemplo, algumas passagens literárias em que o devedor é tratado como alguém sem qualquer respeito e dignidade. Em primeiro lugar, na obra de William Shakespare, "O mercador de Veneza", a personagem Shulock diz que um falido é "outro mau companheiro de negócios que arranjei: um falido, um pródigo, que mal ousa mostrar a cabeça no Rialto; um mendigo que antes se apresentava tão vaidoso no mercado; ele que tome cuidado com aquela letra.". Na referida letra, o mercador oferecia como garantia de pagamento um pedaço de seu próprio coração (MAMEDE, 2018). O segundo exemplo está na obra "O Conde de Monte Cristo", de Alexandre Dumas, onde o personagem Morrel, ao saber que naufragara o seu navio com todas as suas mercadorias, o que o deixaria em péssimas condições financeiras, tenta cometer suicídio, explicando para o seu filho que a vergonha em se tornar pobre, "falido", ou insolvente, é mais dolorosa do que a morte (MAMEDE, 2018).

Ademais, em outros momentos históricos, como na Roma Antiga e na Idade Média, o devedor precisava pagar as suas dívidas com o seu próprio corpo ou, até mesmo, com a própria vida, sendo escravizado, morto, mutilado, dentre outros meios cruéis de se tratar uma pessoa insolvente.

Entretanto, é evidente que o estado de insolvência pode se originar de atos dolosos, fraudulentos, desonestos, mas, como nos dois exemplos literários anteriormente mencionados, muitas vezes a pobreza pode alcançar uma pessoa por meros infortúnios, por questões sociais, locais. Outrossim, nos dias atuais, um empresário pode chegar ao estado de falência por má administração, pela alta taxa de impostos, pela alta concorrência, por não ter investido as suas economias em uma atividade que, de fato, Ihe era mais apropriada, ou seja, via de regra, a fraude não é o motivo da falência, apesar de, etimologicamente, o seu significado ser o de falsear, de enganar. Isto porque o fracasso é inerente a qualquer ação humana. Qualquer ato pode resultar em coisas boas ou ruins. Neste ínterim, no mundo empresarial, o fracasso pode resultar na falência de um empresário ou de uma sociedade empresária. 
Assim, com a insolvência jurídica dos empresários, ocorre, em regra, o inadimplemento de suas obrigações, o que faz com que o Estado precise intervir na relação entre credor e devedor empresário, visando atender aos direitos dos credores de receberem aquilo que foi outrora estipulado entre o credor e o devedor empresário (MAMEDE, 2018).

Ainda, com a grave crise financeira que assola o Brasil há alguns anos, bem como diante do Princípio da Preservação da Empresa e da Livre Concorrência, instituídos pela Constituição Federal, tendo em vista os diversos lucros que as empresas geram (empregos, produção de bens e serviços, etc.), foi necessário que o legislador brasileiro instituísse a nova Lei de Falências e de Recuperação Judicial e Extrajudicial, qual seja, a Lei $n .$. $11.101 / 05$, com o fim de se conseguir a preservação da empresa, dando um tratamento diferenciado para o devedor empresário.

Também é necessário mencionar que a Lei n. ${ }^{\circ} 11.101 / 05$ não se aplica a todas as empresas, uma vez que a referida legislação não se aplica às empresas públicas e sociedades de economia mista; às instituições financeiras públicas ou privadas, cooperativas de crédito, consórcios, entidades de previdência complementar, sociedades operadoras de plano de assistência à saúde, sociedades seguradoras, sociedades de capitalização e outras entidades legalmente equiparadas às anteriores, nos termos dos incisos I e II, do artigo $2^{\circ}$, da LRF.

Ademais, também não são exigíveis do devedor, na recuperação judicial ou na falência as obrigações a título gratuito e as despesas que os credores fizerem para tomar na recuperação judicial ou na falência, salvo as custas judiciais decorrentes de litígio com o devedor, conforme preleciona os incisos I e II, do artigo 5으, da Lei $n . \stackrel{0}{11}$, 101/05.

Desta forma, após a tramitação regular do processo falimentar, ao final, há a possibilidade de o juiz proferir dois pronunciamentos: uma sentença com a decretação da falência ou uma com a improcedência do pedido de decretação da falência do devedor empresário.

No que tange à decisão que é objeto deste estudo, deve-se destacar que ela é uma sentença, de acordo com a doutrina majoritária, uma vez que contém relatório, fundamentação e dispositivo. Ademais, ela também condenará o sucumbente ao pagamento dos honorários e das despesas processuais. Como é em razão desta decisão que há a instauração da falência propriamente dita, ela deve conter uma série de elementos específicos, necessários ao prosseguimento do processo com a maior segurança e efetividade possível. Esses elementos são elencados pelo artigo 99 da Lei n. 11.101/05.

Desta forma, para se saber qual recurso interpor contra o pronunciamento do Juízo falimentar, há duas possibilidades. Caso a decisão julgue procedente a ação de falência e ocorra a decretação do estado falimentar do devedor empresário ou da sociedade empresária, caberá o recurso de agravo de instrumento (artigo 1.015, do CPC). Entretanto, se for proferida sentença que julgue improcedente o pedido, caberá apelação (art. 1.009, CPC), nos termos do artigo 100, da Lei $n .011 .101 / 05$.

Por fim, como na própria lei de falências e recuperação judicial ou extrajudicial há divergência sobre a natureza da decisão que decreta a falência do devedor, passaremos a analisar os pronunciamentos do juiz, de acordo com a legislação processual civil em vigor no Brasil, bem como as naturezas jurídicas dos atos do magistrado a seguir.

\section{PRONUNCIAMENTOS JUDICIAIS NO CÓDIGO DE PROCESSO CIVIL DE 2015}

Os atos do juiz são pronunciamentos e atos materiais. No presente trabalho, daremos atenção a dois pronunciamentos, dispostos no artigo 203, do CPC: decisões interlocutórias e sentenças.

Diferentes dos despachos, as decisões interlocutórias e as sentenças são pronunciamentos decisórios. 
Sentença é o pronunciamento decisório que, com a ressalva do que se preveja especificamente para algum procedimento especial, põe fim à fase cognitiva do

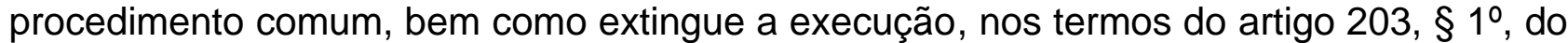
CPC. Assim, a sentença seria o pronunciamento decisório capaz de dar por encerrada a fase cognitiva ou executiva dentro de um processo.

De outro norte, decisão interlocutória é o pronunciamento decisório que não se enquadre na definição de sentença, nos termos do artigo 203, §º , do CPC.

Neste sentido, salienta-se que o que distingue as decisões interlocutórias das sentenças não é a matéria, mas sim a maneira como são enfrentadas as questões a ela submetidas. A prolação da sentença encerra definitivamente a atividade de cognição ou a atividade de execução sobre o seu objeto, já a decisão interlocutória é todo ato processual judicial que resolve, sem colocar fim à atividade de conhecimento ou de execução, questões processuais ou de mérito ao longo do procedimento.

No que tange à decisão que julga procedente a ação de falência, parte da doutrina sustenta que é uma decisão interlocutória, como também há, majoritariamente, doutrinadores que sustentam que este ato do juiz seria uma sentença. Assim, salienta-se que a própria Lei n.․ 11.101/05 não padroniza a terminologia que dá a este pronunciamento judicial, chamando às vezes de decisão, como nos artigos 99, parágrafo único, e 100, ambos da supracitada lei, e, às vezes, de sentença, conforme consta nos artigos 99, caput, e 180 da aludida lei.

Entretanto, não há dúvidas que a decisão que julga procedente a ação de falência se trata de uma sentença, seguindo o que diz a doutrina majoritária.

Pois bem.

Como dito anteriormente, nos termos do artigo 203, $\S 1^{\circ}$, do Código de Processo Civil de 2015, sentença é o pronunciamento por meio do qual o juiz, com fundamento nos artigos 485 e 487, do referido códex processual, põe fim à fase cognitiva do procedimento comum, bem como extingue a execução. Assim, destaca-se que o traço distintivo das sentenças é justamente o seu conteúdo. Além disso, o referido pronunciamento judicial é o ato que, analisando ou não o mérito da demanda, encerra uma das etapas (cognitiva ou executiva) do procedimento em primeira instância.

Ainda, tem-se que a sentença é um provimento decisório, seja de todo o mérito, seja de uma parte dele, seja de uma questão de competência ou outra prejudicial. Da mesma maneira, a sentença, via de regra, é a provisão do juiz que recebendo ou rejeitando a demanda do autor, afirma a existência ou a inexistência de uma vontade concreta da lei que the garanta um bem ou respectivamente a existência ou a inexistência de lei que garanta um bem ao réu (MARINONI, 2016).

Assim, diante de todo o exposto, não há dúvidas de que o pronunciamento judicial que decreta a falência é uma sentença, visto que se trata da definição do mérito do pedido realizado, encaixando-se perfeitamente no conceito de sentença do artigo 203 , $\S 1$ o, do $\mathrm{CPC} / 2015$. Ademais, é com a sentença que decreta a falência que ocorre o fim de uma fase do procedimento (a pré-falimentar ou "fase de conhecimento") e o início de outra, qual seja, a fase falimentar do procedimento ("fase de execução" ou "de cumprimento de sentença"), adequando-se à uma das finalidades de uma sentença.

\subsection{NATUREZAS JURÍDICAS DAS SENTENÇAS}

\subsubsection{SENTENÇA DECLARATÓRIA}

Apenas "declara" a existência, a inexistência ou o modo de ser de uma situação jurídica. 
O objeto desta sentença é eliminar a incerteza sobre a existência, a inexistência ou o modo de ser de uma situação jurídica porque, tão logo a prolação da sentença, será declarada uma situação jurídica. Exemplo: inexistência ou não de um débito.

No entanto, a sentença declaratória não tem a capacidade de impedir ou não uma pessoa de fazer ou não fazer algo. Para tal finalidade, há as sentenças mandamental e executiva. Com a sentença declaratória não se declaram fatos. Declaram-se relações jurídicas (MARINONI, 2016).

\subsubsection{SENTENÇA CONSTITUTIVA}

Todas as sentenças contêm declaração. No caso das sentenças constitutivas e declaratórias, bastam por si para atender o direito do autor. Diferente de uma sentença executiva, em que o autor ainda precisa propor a execução para fazer valer a sentença, uma sentença constitutiva que, por exemplo, rescinde um contrato, vale por si só apenas com a sua prolação (MARINONI, 2016).

Nesta senda, frisa-se que a sentença constitutiva pode criar, modificar ou extinguir uma situação jurídica. Ela pode ser constitutiva positiva (exemplo: constituir/decretar o estado de interdito) ou negativa/desconstitutiva (ex: desconstituir uma relação conjugal).

\subsubsection{SENTENÇA CONDENATÓRIA}

A sentença condenatória também é declaratória (MARINONI, 2016). A diferença é que esta não vale por si só. Para que ela atinja a sua finalidade, é necessário que o vencedor da sentença proponha a execução para fazer valer os efeitos da sentença.

Ademais, pontua-se que a sentença condenatória é necessária para sancionar concretamente o responsável por um ato ilícito (direito penal) ou pelo descumprimento de uma obrigação (direito civil), sendo que isto é feito através da sanção contida na condenação, que possibilita a prática de atos materiais pelos agentes do Estado, ou seja, a execução forçada.

\subsubsection{SENTENÇA MANDAMENTAL}

É caracterizada por dirigir uma ordem para coagir o réu. Tem como objetivo convencer o réu a observar o direito por ela declarado. No caso desta sentença, ocorre a execução "indireta", diferente da condenatória, onde há a execução forçada.

Na mandamental, há ordem e coerção da vontade do réu, o que não acontece na condenatória, onde o cumprimento da sentença acontece após requerimento do credor, que leva aos atos de expropriação de bens do devedor, quando este não cumpre o débito voluntariamente, por exemplo.

Destaca-se que a sentença mandamental também é condenatória (MARINONI, 2016). É uma sentença condenatória cuja efetivação se dá exclusivamente através do emprego de meios coercitivos, como multa, por exemplo.

\subsubsection{SENTENÇA EXECUTIVA}

É aquela que contém a determinação para que se instaure a fase de execução ou de cumprimento de sentença, desenvolvendo-se no mesmo processo (MARINONI, 2016). 


\section{DIVERGÊNCIA DOUTRINÁRIA E JURISPRUDENCIAL ACERCA DO TEMA}

Conforme exposto anteriormente no presente projeto, há uma longa divergência doutrinária e jurisprudencial no que tange à natureza jurídica da decisão que julga procedente a ação de falência.

São muitos os doutrinadores que defendem a natureza declaratória da decisão objeto do presente estudo, como J C Sampaio de Lacerda, que entende que "a sentença declaratória vem reconhecer a situação jurídica do empresário insolvente, declarando-o falido para o fim de daí em diante sujeitar-se aos efeitos que essa nova situação traz, efeitos esses previstos na lei" (LACERDA, J. C. Sampaio de. Manual de direito falimentar. 7. ed. melh. e atual. Rio de Janeiro: Freitas Bastos, 1972, p. 81).

Ademais o doutrinador Rubens Requião sustenta a sua tese de que a sentença teria a natureza jurídica declaratória porque "dá-se o estado de direito (estado falimentar) em virtude da sentença judicial, que não cria, mas pressupõe e por isso apenas declara o estado de falência" (REQUIÃO, Rubens. Curso de direito falimentar. 17. ed. atual. por Rubens Edmundo Requião São Paulo: Saraiva, 1998, p. 106, v. 1.).

No âmbito jurisprudencial, a ministra Nancy Andrighi, relatora no julgamento do Recurso Especial № 1.660.198 - SP (2016/0086883-0), mencionou no seu voto que a natureza jurídica da sentença de quebra é declaratória.

De outro norte, há diversos doutrinadores que defendem a natureza constitutiva da sentença que decreta a falência, como afirma Miranda (2004, p. 3393):

A constitutividade da sentença de declaração de abertura de falência é preponderante. Após ela, há um estado jurídico que não existia... A sentença de forte carga declarativa abre as portas para a execução forçada coletiva. A força da decisão é constitutiva. Compreende-se facilmente que assim seja, porque entre outros efeitos, tem a decisão de admissão do concurso de credores, o efeito de suspender as ações executivas singulares. Ficam absorvidas na execução coletiva e exercendo-se essa sobre todo o patrimônio do falido, caindo no vácuo a execução singular, ou então os dois procedimentos se chocariam.

Neste mesmo sentido, afirma Jr., Fazzio (2017, p. 639-641):

$\mathrm{Na}$ medida em que produz uma nova situação jurídica (o concurso de credores, a execução coletiva incidente sobre o patrimônio do devedor), a sentença que decreta a falência do devedor é um provimento jurisdicional de conhecimento na modalidade constitutiva, produtor do estado jurídico de falência.

Outros grandes doutrinadores como Nelson Abrão, Ecio Perin Júnior e Fábio Ulhoa Coelho, também defendem em suas obras a constitutividade da sentença que decreta a falência. Em se tratando do último doutrinador citado, há que se destacar que, em que pese a ministra Nancy Andrighi tenha fundamentado o seu voto com uma obra de Fábio Ulhoa Coelho, com o fim de corroborar que a natureza jurídica seria declaratória, merece se destacar que o mencionado doutrinador apresenta em sua obra o seu entendimento de que a natureza jurídica seria constitutiva, conforme afirma Coelho (2008, p.272):

Dentro desse contexto, pode-se concluir que, apesar do nome de que fez uso o legislador, a sentença declaratória da falência, pressuposto inafastável da instauração do processo de execução concursal de empresário, tem caráter predominantemente constitutivo.

Esse é o entendimento predominante da doutrina. Com a sua edição pelo juiz, opera-se a dissolução da sociedade empresária falida, ficando seus bens, atos jurídicos, contratos e credores submetidos a um regime jurídico específico, 0 falimentar, diverso do regime geral do direito das obrigações. É a sentença 
declaratória da falência que introduz a falida e seus credores nesse outro regime. Ela não se limita, portanto, a declarar fatos ou relações preexistentes, mas modifica a disciplina jurídica destes, daí o seu caráter constitutivo.

Além de todo o acima exposto, afirma Almeida (2013, p. 250):

Por outro lado, conquanto declaratória, por isso que reconhece o estado de quebra preexistente, possui, inquestionavelmente, natureza constitutiva, na medida em que, como acentua Miranda Valverde, instaura um novo estado jurídico - o de falência. [...]

Ora, a sentença, efetivamente, antes de tudo, reconhece o direito preexistente - essa, aliás, a sua principal função, aplicando a lei ao caso concreto. Todavia, o que a sentença constitutiva traz no seu bojo é a criação, modificação ou extinção de um estado ou relação jurídica.

Enquanto a sentença declaratória reconhece a existência ou inexistência de fatos preexistentes, a constitutiva cria uma situação inteiramente nova.

Em verdade, conquanto os fatos determinantes da falência já existam anteriormente à quebra, o devedor só é considerado falido com sentença falimentar.

Por outras palavras, ninguém é considerado falido, malgrado impontual e até insolvente, sem sentença que o declare como tal.

Por fim, para tornar o debate acerca do tema ainda mais complexo, há doutrinadores que entendem que a natureza jurídica do pronunciamento judicial em questão não pode ser definida apenas como constitutiva ou declaratória, mas sim como de natureza híbrida (MAMEDE, 2018) ou de caráter misto (VALVERDE, 1962) e, até, de tratar-se de uma sentença executiva (PACHECO, 2009), em razão do seu conteúdo e eficácia no mundo jurídico.

\section{NATUREZA JURÍDICA DA DECISÃO QUE JULGA PROCEDENTE A AÇÃO DE FALÊNCIA}

Diante de todo o conteúdo apresentado na presente pesquisa, resta claro que a sentença que decreta a falência possui natureza jurídica constitutiva, uma vez que ela inicia uma nova fase na vida econômica do falido, modificando suas relações jurídicas.

Neste sentido, em que pese haja uma carga declaratória nessa sentença, na medida em que ela reconhece a insolvência do devedor empresário, frisa-se que essa carga declaratória se agrega e prepondera a eficácia constitutiva, com a modificação e a extinção de relações jurídicas do falido.

Ademais, o referido pronunciamento judicial cria situações jurídicas novas, constitui um status jurídico de falido e modifica as relações jurídicas entre o falido, seus credores e terceiros em geral. Outrossim, é com a sentença que um devedor empresário se torna falido, ou seja, nasce a falência a partir de quando a sentença é proferida, o que destaca a sua natureza constitutiva, por possuir efeitos ex nunc, diferente das sentenças preponderantemente declaratórias, que geram efeitos ex tunc.

\section{CONCLUSÃO}

Com a presente pesquisa, buscou-se esclarecer que a classificação das decisões judiciais não tem por base a exclusividade de um determinado provimento jurisdicional, mas a preponderância de um deles. $\mathrm{E}$, isto é assim, porque toda decisão, inclusive a condenatória e a constitutiva, possui um conteúdo declaratório. Mas como trazem um outro conteúdo, passam a pertencer à categoria diversa. 
Desta forma, pretendeu-se demonstrar que a natureza jurídica da decisão que julga a ação de falência é indiscutivelmente constitutiva. Isto porque, embora referida decisão declare a insolvência jurídica do empresário, ela vai além, constituindo o estado falimentar do devedor empresário.

Desta forma, ao analisar-se a classificação trinária das decisões judiciais, percebese que todas elas possuem um conteúdo declaratório, de forma que apenas as que se limitam a isto podem ser consideradas meramente declaratórias.

\section{REFERÊNCIAS}

ALMEIDA, Amador Paes de. Curso de direito de falência e recuperação de empresas. 27ª Ed. São Paulo: Saraiva, 2013.

COELHO, Fábio Ulhoa. Comentários à nova lei de falências e de recuperação de empresas. (Lei no 11.101, de 9/2/2005). 5ª̣ ed. São Paulo: Saraiva, 2008.

Jr., FAZZIO, Waldo. Manual de Direito Comercial. 18ª edição. Atlas, 2017.

LACERDA, J. C. Sampaio de. Manual de direito falimentar. 7. ed. melh. e atual. Rio de Janeiro: Freitas Bastos, 1972.

MAMEDE, Gladston. Direito Empresarial Brasileiro: Falência e Recuperação de Empresas. 9ª Ed. São Paulo: Atlas, 2018.

MARINONI, Luiz Guilherme. Novo curso de processo civil: tutela dos direitos mediante procedimento comum, volume II/Luiz Guilherme Marinoni, Sérgio Cruz Arenhart, Daniel Mitidiero. $2^{\underline{a}}$ ed. São Paulo: Editora Revistas dos Tribunais, 2016.

MIRANDA, Francisco Cavalcanti Pontes. Tratado de Direito Privado. Tomo - Vol.XXX. $1^{\text {a }}$ ed. Bookseller, 2004.

PACHECO, José da Silva. Processo de recuperação judicial, extrajudicial e falência. 3aㅡ. Ed. Rio de janeiro: Forense, 2009.

REQUIÃO, Rubens. Curso de direito falimentar. 17. ed. atual. São Paulo: Saraiva, 1998.

TOMAZETTE, Marlon. Curso de direito empresarial: Falência e recuperação de empresas. V. 3. 5. Ed. rev. E atual. São Paulo: Atlas, 2017.

VALVERDE, Trajano de Miranda. Comentários à lei de falências. Rio de Janeiro: Forense, 1962.

BRASIL. Superior Tribunal de Justiça. Resp n 1660198/SP. Recorrente: Oliveira Trust Distribuidora de Títulos e Valores Mobiliários S/A. Recorrida: Procid Participações e Negócios S/A - FALIDA. Relatora: Ministra Nancy Andrighi. Brasília, DF, 03 de agosto de 2017. Diário Oficial da União. Brasília. 